Revista Destaques Acadêmicos, Lajeado, v. 9, n. 3, 2017. ISSN 2176-3070

DOI: http://dx.doi.org/10.22410/issn.2176-3070.v9i3a2017.1432

www.univates.br/revistas

\title{
ESTÁGIO SUPERVISIONADO: UMA PESQUISA COM ESTUDANTES DE PSICOLOGIA
}

\author{
Cristiane Guaragni ${ }^{1}$, Alice Grasiela Cardoso Rezende Chaves ${ }^{2}$
}

Resumo: O presente artigo buscou investigar as percepções dos estagiários do curso de Psicologia em uma instituição comunitária de ensino superior situada no interior do Rio Grande do Sul/BR, em relação ao processo de estágio. De um total de 59 estagiários, foram entrevistados 20, sendo que 10 desses estudantes estavam cursando o Estágio Supervisionado Básico I e os outros 10 o Estágio Supervisionado Específico I. Este estudo caracterizado como qualitativo e exploratório, utilizou para a análise dos dados a Análise do Discurso. Os resultados encontrados enfatizam que o resgate de conceitos durante o estágio é inerente à formação, tornando assim sua prática mais enriquecedora, o que é favorecido por uma carga horária maior. Além disso, os entrevistados relataram a importância da supervisão local e a orientação acadêmica, por auxiliarem o estagiário a nortear a sua prática. $\mathrm{O}$ processo seletivo, apesar de ser visto como uma experiência causadora de ansiedade traz experiência para as futuras seleções as quais os estagiários irão participar. Por fim, em relação ao processo avaliativo do estágio, foi evidenciado durante a realização desta pesquisa, que os estudantes dão maior importância à prática do estágio do que à sua avaliação, explicitando assim, a importância da vivência do estágio para o acadêmico do curso de Psicologia.

Palavras-chave: Estágio. Psicologia. Estudantes.

\section{INTRODUÇÃO}

O desejo de aprofundar os conhecimentos a respeito do processo de estágio do curso de Psicologia surgiu após a inserção de uma das autoras do presente artigo no Estágio Supervisionado Básico I, no primeiro semestre do ano de 2016. A partir desse momento, ela passou a conviver com outros

1 Acadêmica do curso de Psicologia da Univates, Lajeado/RS.

2 Graduada em Psicologia pela Universidade Federal de Sergipe, especialista em Terapia Conjugal e Familiar, pela Faculdade de Sergipe, mestre em Psicologia Social e Institucional pela Universidade Federal do Rio Grande do Sul. Docente do curso de Psicologia da Univates, Lajeado/RS. 
estagiários do curso e a participar de pequenas rodas de conversa informais para discutir e refletir sobre o processo de estágio.

Como aluna e estagiária, pode vivenciar o processo de estágio intensamente, e em consequência disso, sua análise de implicação foi fundamental para a análise dos dados produzidos no campo em que estava inserida. Sob o olhar de Nascimento e Coimbra (2008, p. 147), “utilizar a análise de implicações é tornar visível e audível as forças que nos atravessam, nos afetam e nos constituem cotidianamente".

A partir disso, esta pesquisa teve como objetivo central investigar as percepções dos acadêmicos do curso de Psicologia em relação aos estágios Básico e Específico, em uma instituição comunitária de ensino superior (IES) situada no interior do Rio Grande do Sul/BR.

Dentro desse objetivo, o estudo pretendeu investigar e analisar as percepções dos estagiários em relação à carga horária dos estágios, aos momentos de supervisão local e orientação acadêmica, o processo de seleção para o estágio, o processo avaliativo e também quanto à adequação do oferecimento das disciplinas dentro da matriz curricular do curso de Psicologia.

Para a contextualização do tema deste artigo e da importância dos estágios supervisionados, considera-se importante mencionar algumas informações a respeito da organização e das diretrizes curriculares do curso de Psicologia.

\section{APORTES TEÓRICOS}

O curso de Psicologia foi regulamentado no Brasil em 27 de agosto de 1962. A partir de então, a clínica logo se estabeleceu como uma área nobre de atuação do psicólogo. No entanto, gradativamente, houve a ascensão de novas modalidades de trabalho, como a da psicologia social e de saúde mental, construindo assim uma nova face para a psicologia (NETO, 2010).

A partir do ano de 1995, segundo Carvalho e Sampaio (1997), o Conselho Federal de Psicologia (CFP) passou a identificar o psicólogo conforme as seguintes áreas: Psicólogo Clínico, Psicólogo do Trabalho, Psicólogo do Trânsito, Psicólogo Educacional, Psicólogo Jurídico, Psicólogo do Esporte, Psicólogo Social e Professor de Psicologia.

Recentemente, em 15 de março de 2011, o Ministério da Educação emitiu a Resolução $\mathrm{n}^{\circ} 5$ que institui as Diretrizes Curriculares Nacionais (DCN) para os cursos de graduação em Psicologia, afirmando em seu art. $3^{\circ}$ que "o curso de graduação em Psicologia tem como meta central a formação do psicólogo voltado para a atuação profissional, para a pesquisa e para o ensino de Psicologia".

As Diretrizes Curriculares Nacionais também apontam em seu art. $10^{\circ}$ que: 
Pela diversidade de orientações teórico-metodológicas, práticas e contextos de inserção profissional, a formação em Psicologia diferencia-se em ênfases curriculares, entendidas como um conjunto delimitado e articulado de competências e habilidades que configuram oportunidades de concentração de estudos e estágios em algum domínio da Psicologia.

Conforme o art. 20 de tais Diretrizes, os estágios obrigatoriamente devem fazer parte da formação. Eles representam um conjunto de atividades planejadas e supervisionadas pelos professores da instituição de ensino, propiciando assim, a articulação entre a teoria vivenciada durante o curso com a prática e a postura profissional do estudante (BRASIL, 2011).

A Lei $n^{\circ} 11.788$, aprovada em 25 de setembro de 2008 e que dispõe sobre o estágio de estudantes, define-o em seu art. $1^{\circ}$ como:

[...] ato educativo escolar supervisionado, desenvolvido no ambiente de trabalho, que visa à preparação para o trabalho produtivo de educandos que estejam frequentando o ensino regular em instituições de educação superior, de educação profissional, de ensino médio, da educação especial e dos anos finais do ensino fundamental, na modalidade profissional da educação de jovens e adultos.

Essa Lei concebe o estágio com o objetivo de propiciar ao aluno um conhecimento do local de trabalho, visando o aprendizado de competências próprias da atividade profissional e a contextualização curricular.

Conforme Carvalho e Sampaio (1997, p.19), o "estágio como lugar de iniciação a uma prática e, ao mesmo tempo, de reflexão teórica, pode representar um espaço de criação, de construção de conhecimento, pelo desafio da situação nova".

O estágio representa um momento na vida acadêmica do aluno que simboliza a chance de vivenciar a prática no campo de trabalho (Campos, 2009). Seguindo essa linha de pensamento, o aluno universitário, primeiramente, precisa cursar diversas disciplinas do curso de graduação, para então depois poder vivenciar o estágio e, finalmente, poder colocar em prática os conhecimentos teóricos e práticos adquiridos.

Do mesmo modo, Mafuani (2011) explica que quando o aluno chega na universidade sente dificuldade em relacionar teoria e prática, por isso, é necessária a vivência da realidade que o estágio é capaz de propiciar.

As autoras Scalabrin e Molinari (2013, p. 4) confirmam que o estágio "é compreendido como um processo de experiência prática, que aproxima o acadêmico da realidade de sua área de formação e o ajuda a compreender diversas teorias que conduzem ao exercício da sua profissão". 
A esse respeito, a Carta de Serviços sobre Estágios e Serviço-Escola (CFP, 2013, p. 12), explica que há duas modalidades de estágio em Psicologia: o estágio Básico, que "visa o desenvolvimento de práticas integrativas das competências e habilidades previstas no núcleo comum de formação", partindo dos processos de baixa complexidade e indo em direção aos desafios mais complexos, e o estágio Específico, caracterizado por "incluir o desenvolvimento de práticas integrativas dos conhecimentos, habilidades e competências ligadas a cada uma das ênfases curriculares propostas pelo curso" (CFP, 2013, p. 13), concentrando assim as atividades mais voltadas à ênfase escolhida pelo estagiário.

Diante do exposto, pode-se afirmar que o momento do estágio é crucial para o acadêmico ter a oportunidade de refletir sobre a profissão que escolheu, tendo em vista que este é o momento de vivenciar, pensar, interagir e construir através de dispositivos e teorias conhecidas nos anos de estudo anteriores.

\section{PROCEDIMENTOS METODOLÓGICOS}

A presente pesquisa se desenvolveu no primeiro semestre do ano de $2017^{3}$. Inicialmente, foi enviado um e-mail pela coordenação do curso de Psicologia aos estudantes que estavam matriculados no Estágio Supervisionado Básico I e no Estágio Supervisionado Específico I, explicando o tema da pesquisa e convidando-os a participarem. Solicitou-se à coordenadora que enviasse o e-mail para que os acadêmicos se sentissem à vontade em responder se queriam ou não participar, o que talvez não ocorreria caso a autora, que também é estagiária do curso, encaminhasse o e-mail.

A ordem de escolha dos participantes se deu pela manifestação de interesse em participar da pesquisa através do e-mail enviado. Após a adesão dos participantes ao estudo, a coleta de dados com os estagiários ocorreu nos meses de março e abril de 2017.

O instrumento utilizado na pesquisa foi uma entrevista semiestruturada que continha algumas questões norteadoras, responsáveis por introduzir o tema do estágio e suas etapas, como: o processo seletivo, a influência da organização da matriz curricular do curso de Psicologia, a carga horária, as relações com o supervisor local e o orientador acadêmico e o processo avaliativo do estágio.

As entrevistas foram aplicadas em 20 participantes de um total de 59 acadêmicos que estavam matriculados em estágios, sendo que 10 cursavam o Estágio Supervisionado Básico I e os outros 10 o Estágio Supervisionado Específico I do curso de Psicologia. Os campos de estágios dos participantes da pesquisa variam entre clínica-escola, setor de recursos humanos em organizações, centros de referência em assistência social, centros de atenção

3 O projeto da presente pesquisa foi encaminhado e, posteriormente, aprovado pelo Comitê de Ética e Pesquisa (COEP) da instituição de ensino pesquisada, sob o número CAEE 64759017.6.0000.5310. Após essa liberação foi dado início à sua realização. 
psicossocial, serviço de assistência jurídica e Associação de Pais e Amigos dos Excepcionais.

As entrevistas foram realizadas em locais de escolha do próprio entrevistado e foram agendadas em datas e horários também definidos por eles, evitando transtornos em função da pesquisa.

As informações apenas foram coletadas após a leitura e assinatura do Termo de Consentimento Livre e Esclarecido (TCLE). Tais informações foram gravadas e transcritas para posterior análise. Para garantir a confidencialidade e o anonimato dos estudantes que participaram das entrevistas, estes estão representados neste artigo pela sigla E.B. quando se trata de falas de alunos que estavam no Estágio Supervisionado Básico I, e pela sigla E.E. quando o aluno for do Estágio Supervisionado Específico I.

O presente estudo caracteriza-se, quanto à natureza, como qualitativo e exploratório. O caráter qualitativo é explicado por Gil (2010, p. 90): “[...] nas pesquisas de cunho qualitativo, [...], costuma-se verificar um vaivém entre observação, reflexão e interpretação à medida que a análise progride, o que faz com que a ordenação lógica do trabalho torne-se significativamente mais complexa".

Conforme Minayo e Sanches (1993, p. 245), o "material primordial da investigação qualitativa é a palavra que expressa a fala cotidiana, seja nas relações afetivas e técnicas, seja nos discursos intelectuais, burocráticos e políticos". Tal afirmação vem ao encontro do fato da entrevista utilizada ser semiestruturada, prezando assim pela integridade das informações coletadas.

De acordo com os autores supracitados, o objetivo da pesquisa qualitativa é observar e refletir sobre as informações, e não realizar uma tabulação, não sendo importante o número total de sujeitos entrevistados, mas sim o conteúdo que foi captado.

Ainda segundo Minayo e Sanches (1993, p. 246),

[...] uma análise qualitativa completa interpreta o conteúdo dos discursos ou a fala cotidiana dentro de um quadro de referência, onde a ação e a ação objetivada nas instituições permitem ultrapassar a mensagem manifesta e atingir os significados latentes.

Esta pesquisa também se caracteriza como exploratória, pois o pesquisador desse tipo de investigação mantém contato direto com o campo em que se desenvolverá a pesquisa, buscando familiarizar-se ainda mais com o problema, além de buscar a literatura existente relacionada ao tema (GIL, 2010).

Os dados obtidos através das entrevistas foram analisados conforme a análise do discurso de Michel Foucault. Para Fischer, 
[...] é preciso ficar (ou tentar ficar) simplesmente no nível de existência das palavras, das coisas ditas. Isso significa que é preciso trabalhar arduamente com o próprio discurso, deixando-o aparecer na complexidade que lhe é peculiar. E a primeira tarefa para chegar a isso é tentar desprender-se de um longo e eficaz aprendizado que ainda nos faz olhar os discursos apenas como um conjunto de signos, como significantes que se referem a determinados conteúdos, carregando tal ou qual significado, quase sempre oculto, dissimulado, distorcido, intencionalmente deturpado, cheio de "reais" intenções, conteúdos e representações, escondidos nos e pelos textos, não imediatamente visíveis. É como se no interior de cada discurso, ou num tempo anterior a ele, se pudesse encontrar, intocada, a verdade, desperta então pelo estudioso (FISCHER, 2001, p.198).

De acordo com Michel Foucault (2012, p. 46), o "discurso nada mais é do que a reverberação de uma verdade nascendo diante de seus próprios olhos". $\mathrm{O}$ autor afirma ainda que o discurso se trata de "um jogo de escritura no primeiro caso, de leitura no segundo, de troca no terceiro, e essa troca, essa leitura e essa escritura não põem em jogo senão os signos".

Tendo em vista as afirmações acima mencionadas, e considerando que uma das autoras é estagiária e a outra orientadora acadêmica de estágio, durante a análise dos dados ambas tiveram de se desprender de teorias ou mesmo de discursos tidos como verdadeiros, e precisaram se manter abertas às falas que surgiram durante as entrevistas, atentando assim para os discursos como um todo, observando suas entrelinhas.

\section{RESULTADOS E DISCUSSÃO}

Os resultados encontrados através da realização desta pesquisa foram organizados em cinco categorias de análise. A primeira delas versa sobre como os estagiários percebem a matriz curricular do curso e se esta os prepara para a experimentação do estágio. A segunda se refere às impressões sobre o processo seletivo para o estágio. A terceira categoria traz as percepções acerca da carga horária do estágio que os estudantes realizam. Na quarta categoria, o artigo traz as percepções sobre os momentos de supervisão local e orientação acadêmica e, por fim, a quinta apresenta o entendimento dos estagiários acerca do processo avaliativo.

\subsection{A matriz curricular e a preparação para entrar em estágio}

$\mathrm{Na}$ IES onde o estudo foi realizado, o curso de Psicologia é composto por 60 disciplinas organizadas em 10 semestres. A matriz curricular está disposta de modo que disciplinas que envolvem conteúdos mais amplos são disponibilizadas nos primeiros semestres do curso, enquanto que conteúdos 
mais específicos, bem como estágios e trabalho de conclusão de curso, são ofertados nos últimos semestres do curso.

Durante a realização da pesquisa, quando questionados sobre a organização da matriz curricular do curso, seis entrevistados trouxeram o fato de que algumas disciplinas do início do curso deveriam ser ofertadas mais próximas ao período de estágio, para que não fosse necessário recorrer às disciplinas iniciais para recuperar conceitos e teorias já estudadas. Isso pode ser observado no relato: "[...] sinto dificuldade aqui no estágio, principalmente, é que as disciplinas de políticas públicas e saúde mental coletiva foram muito no início, daí então tem que estar recuperando alguns conceitos" (E.B.1).

Vale lembrar que o currículo de um curso de graduação passa por criteriosa análise e considera os níveis de complexidade dos conteúdos em sua organização. Conforme já mencionado, as disciplinas iniciais possuem a função de fornecer escopo aos acadêmicos para que compreendam as disciplinas de caráter mais específico, que são disponibilizadas do meio para o final do curso.

É importante pensar que o fato de recuperar conceitos ao longo da graduação para a sua utilização durante o estágio é algo que permeia a formação. Como as disciplinas se complementam ao longo do curso, é fundamental que os acadêmicos se mantenham abertos a pesquisar e entrecruzar conteúdos, principalmente durante as práticas, com o objetivo de obter uma formação que os prepare de modo efetivo para o mundo profissional.

Outra informação importante investigada durante a realização da pesquisa foi o modo como as disciplinas teóricas e práticas do curso de Psicologia preparam o aluno para o ingresso no estágio. Nesse sentido, os estagiários ressaltaram que, apesar da prática ser complexa e desafiadora, grande parte do conteúdo que é estudado nas disciplinas é revisto durante a vivência do estágio. Esse aspecto fica evidenciado no comentário a seguir: "[...] eles vêm sendo até bem coerentes, muitas coisas que a gente vê em sala de aula acabam aparecendo de alguma forma [...]" (E.E.1).

A partir do momento que o aluno se vê no campo de estágio tendo que realizar atendimentos, acolhimentos, atividades em grupo, entre outros, se sente desafiado a relembrar os conhecimentos aprendidos em sala de aula. Esse processo desacomoda o aluno, tirando-o da sua zona de conforto.

Alguns conceitos que foram apresentados durante as disciplinas e que naquele momento não pareciam fazer sentido, durante o estágio tomam forma e são imprescindíveis para o entendimento e discussão das atividades desenvolvidas. p. 66):

A afirmação acima vem ao encontro do que é dito por Campos (2009,

No último ano do curso é onde geralmente ouvimos os alunos reclamarem de que não estão preparados para o mercado, que lhes 
falta "muita coisa", que a instituição de ensino não os preparou para o mercado e tantos outros lamentos. O fato é que no estágio o acadêmico se vê, pela primeira vez, "sozinho" para colocar em prática os ensinamentos recebidos.

\subsection{Impressões sobre o processo seletivo}

Conforme Banov (2012, p. 54), “o processo de seleção é composto por: análise de currículo, entrevista, aplicação de testes, dinâmicas de grupo e exame médico específico". A autora também explica em seu estudo que a técnica mais utilizada é a entrevista. No caso dos processos de seleção para os estágios do curso de Psicologia da IES pesquisada, cada campo de estágio tem a autonomia para solicitar os documentos que julgar necessário e realizar o processo seletivo.

$\mathrm{Na}$ IES onde a pesquisa ocorreu, o processo de seleção inicia no semestre anterior ao estágio começar. Ainda no mês de agosto, um e-mail é enviado pela coordenação, solicitando resposta dos alunos que pretendem entrar em estágio no ano seguinte e, a partir disso, uma reunião é agendada com os acadêmicos com o objetivo de realizar as primeiras combinações.

Geralmente, os documentos solicitados para se candidatar ao processo seletivo para estágio são o Currículo Lattes e uma Carta de Apresentação. $\mathrm{O}$ método de seleção é composto por entrevistas em grupo, individuais e apreciação do currículo. Cada aluno deve se organizar e se candidatar ao processo seletivo dos locais que mais lhe interessar.

O processo seletivo ocorre no mês outubro de cada ano e no mês seguinte os campos de estágio comunicam aos estagiários os resultados do processo de seleção. Nesse sentido, seis alunos entrevistados criticaram a forma como ocorre o processo seletivo, devido ao fato de considerá-lo uma fonte de ansiedade e por gerar uma sensação de competição entre os colegas, conforme relato: "[...] a gente conversava, onde tu conseguiu? Tem gurias que conseguiram em quatro lugares e outras que não conseguiram em nenhum, então gera constrangimento, eu nem falava nada porque fazia mal ao outro [...]" (E.B.2).

Neste sentido, oito entrevistados comentaram que consideram o processo longo e cansativo, pois, por receio de ficar sem local para estagiar, acabam se candidatando para vários campos de estágio.

A necessidade de produção de cartas de apresentação para vários espaços e, consequentemente, a participação em muitos processos seletivos apareceu como ponto negativo. A esse respeito, segue a percepção de uma aluna: "[...] eu acho que cria muita ansiedade, muito nervosismo, acho que não precisaria, e é maçante ter de fazer cartas pra todos os lugares, ir a entrevistas. Acho um ponto negativo [...]" (E.E.2).

O processo de seleção para estágio pode se caracterizar como produtor de ansiedade, em virtude do receio de ficar sem campo para estagiar, e também 
por estarem ingressando em uma nova etapa da formação que apresentará atividades diferentes das habituais. Para Rudnicki e Carlotto, os estudantes "tendem a aumentar a ansiedade pelas exigências que o período de estágios lhes impõe, de que assumam uma postura profissional e integrem o que foi aprendido na teoria com a prática" $(2007$, p. 100).

$\mathrm{O}$ autor Cremonese corrobora com a citação acima, mostrando que em pesquisas realizadas com acadêmicos do curso de enfermagem notouse que "a ansiedade é referida como uma forma de estresse, que aparece ao desenvolverem atividades práticas para as quais não se sentem preparados" (2011, p. 94).

Em contrapartida, cinco dos estagiários pesquisados concordam que fazendo o processo seletivo semelhante a uma entrevista de emprego já estão se preparando para ingressar no mercado de trabalho depois de formados, pois entendem que esta experiência é bastante válida. Esse sentimento aparece no relato a seguir: "[...] é uma amostra do mercado de trabalho né, porque depois, numa área tu vai ter que passar por isso, é uma boa experiência [...]" (E.B.3).

A esse respeito, através das informações coletadas nas entrevistas, pode-se verificar que embora ainda estejam realizando os estágios, já é presente a preocupação com a disputa por vagas no mercado de trabalho. Isto é exemplificado na citação a seguir: "[...] eu não tenho uma visão negativa disso, porque eu acho que tu já está te experimentando para o mercado de trabalho, depois tu vai passar por processos assim né? Então ali tu já vivencia um pouquinho [...]" (E.B.4).

Neste item, este estudo corrobora com a pesquisa de Ferreira (2015), na qual os alunos entrevistados consideraram válida a experiência adquirida com o processo seletivo, por deixá-los mais preparados para as próximas seleções que participarão no mercado de trabalho.

Quando questionados sobre algum outro modo que poderia ser utilizado para a seleção de estágio, a maioria dos entrevistados não souberam responder, pois não conseguiam pensar em outras possibilidades de realização. Apenas um aluno especificou algumas outras formas de realizar o processo seletivo: "podia ser pelas notas. A gente se esforça do primeiro ao último semestre para poder entrar num lugar. Podia ser por sorteio" (E.E.3).

\subsection{Percepções sobre a carga horária do estágio}

Conforme o Projeto Pedagógico do curso de Psicologia da IES estudada (UNIVATES, 2015), é exigido que os alunos realizem quatro estágios durante a formação: o Estágio Supervisionado Básico I e II e o Estágio Supervisionado Específico I e II. Cada um deles tem a duração de 180 horas divididas ao longo de um semestre. No total, são 4 semestres em que o aluno mantém contato com algum campo de estágio, seja de assistência social, jurídica, campo educacional, hospitalar ou de psicologia organizacional. 
De cada um dos estágios acima mencionados, 120 horas precisam ser cumpridas dentro do campo de estágio e as 60 horas restantes correspondem ao tempo da orientação, sempre dada por algum professor da instituição de ensino. A carga horária total dos estágios corresponde a até $20 \%$ da carga horária total do curso de graduação. Cada local de estágio possui a autonomia para definir o número de horas que o acadêmico deverá cumprir, desde que varie entre 12 e 20 horas semanais e que não exceda 6 horas diárias.

Durante a realização da pesquisa, a maioria dos estagiários entrevistados concordaram que um número maior de horas representa mais tempo para conhecer o campo de estágio, desenvolver atividades e adquirir experiência. Este aspecto é evidenciado nos relatos abaixo:

[...] acho que se fosse menos tempo não teríamos tanta coisa para fazer, não teríamos tantos atendimentos, não desenvolveríamos tanto, mas se fosse mais seria muito puxado pra gente [...] (E.B.5).

[...] avalio uma carga horária puxada, por serem vários turnos, mas eu acho que se fosse uma carga horária menor, a gente não conseguiria aproveitar tudo que a gente aproveita e se espera que aproveitemos no estágio [...] (E.B.3).

A afirmação acima vem ao encontro do que é dito por Campos (2009, p. 66) "Cabe aos programas de estágio - e os estagiários devem estar atentos a isso - oferecer atividades que promovam a aplicação prática e cotidiana dos conhecimentos recebidos durante a formação acadêmica".

De acordo com a citação acima, percebe-se que o campo de estágio executa a função importante de não somente exigir um número mínimo de horas que devem ser cumpridas, mas, principalmente, de promover atividades para que os estagiários possam praticar durante o tempo que permanecem no campo, experimentando as práticas inerentes ao processo de estágio.

Em contrapartida, alguns dos estagiários consideraram a carga horária excessiva, destacando que os acadêmicos de Psicologia são os únicos dentre os cursos da área da saúde obrigados a permanecer no campo de estágio durante o semestre inteiro, apesar de completarem as 120 horas exigidas antes do final do semestre. Essa afirmação aparece no relato: "[...] eu acho muito ruim porque a gente faz mais que o dobro pedido pelo MEC ou pedido pelo curso, nós teríamos que fazer 120 horas e fazemos 250, 270 horas [...]" (E.E.4).

Conforme os dados investigados, os acadêmicos entendem e reforçam que o vínculo com os usuários dos campos nos quais estagiam é essencial para o desempenho de uma boa prática, e isso só é alcançado através de vivências na área, que são favorecidas por uma carga horária de estágio maior. 


\subsection{As relações com o supervisor local e o professor orientador}

Segundo Buriolla (2001), a importância do supervisor de campo e do orientador acadêmico é ímpar, pois a postura deles irá nortear a atuação do profissional que está se formando. Assim, é essencial que estes profissionais tenham compromisso com a formação do estagiário, incentivando-os na sua autonomia.

Conforme explicam as autoras França e Souza:

Os supervisores acadêmicos e de campo no âmbito da supervisão tem a possibilidade de visualizar e viabilizar novas possibilidades de intervenções adquirindo novos conhecimentos em conjunto com seus estagiários, uma vez que o estágio supervisionado é um momento de construção e desconstrução de paradigmas para todas as partes integrantes (2015, p. 2).

O diálogo entre estagiário, supervisor local e professor orientador deve ser aberto, de modo a contribuir para que o atendimento dispensado pelo estagiário aos usuários que acompanha seja de qualidade. Isto se faz necessário ainda para que o aprendizado do estagiário seja amplo e completo.

A afirmação acima vem ao encontro dos sentimentos dos estagiários entrevistados, segundo o relato de uma aluna: "[...] tem esse espaço pra tá conversando, dialogando e pensar juntas. É um momento que as duas estão aprendendo, ela como profissional, e eu como estagiária [...]" (E.E.5).

O professor orientador e o supervisor local possuem como uma de suas funções ouvir o estagiário a respeito de seus atendimentos, suas aflições e angústias. Além disso, são os responsáveis por realizar a avaliação do estagiário.

Conforme todos os sujeitos da pesquisa relataram, a relação entre estagiário, supervisor local e orientador acadêmico, acontece de forma aberta e tranquila, respeitando as percepções e a disponibilidade de cada um deles, mantendo flexibilidade em relação aos horários e aos meios de comunicação, de acordo com os relatos a seguir:

[...] todas as vezes que fui tirar alguma dúvida, falar sobre algum caso específico ou alguma coisa assim a pessoa foi muito aberta, e muito de "boa" muito tranquila, bem aberta mesmo, me ajudou, sem problemas [...] (E.B.6).

[...] eles estavam sempre dispostos, e quando não podia se encontrar porque eu tinha alguma coisa ou o professor tinha alguma coisa, eles estavam disponíveis pelo WhatsApp e por outras formas, então eu me senti amparada, eu mandava e-mail, eu perguntava antes de fazer alguma coisa [...] (E.E.6). 
A partir das falas de todos os acadêmicos entrevistados, a orientação e a supervisão ocorrem de modo a proporcionar segurança, fazendo com que se sintam amparados para colocar em prática seus conhecimentos nos atendimentos realizados, interferindo positivamente na experimentação do estágio. Isso é demonstrado neste relato: "[...] elas me fazem conseguir direcionar o meu cuidado, ter como posso dizer, de modo geral melhorar a minha prática [...]" (E.E.7).

Corroborando assim com a afirmação de Almeida:

Torna-se perceptível a relevância do trabalho coletivo e integrado da tríade: supervisor de campo, supervisor acadêmico e estagiário, numa perspectiva afirmativa de desenvolvimento do processo de estágio e formação profissional do aluno (2013, p. 13).

O estagiário precisa dialogar com seu supervisor local, para assim compartilhar suas reflexões e dificuldades, sentir-se amparado e posicionar-se frente às situações que poderão surgir, colocando em prática seus conhecimentos e sendo proativo dentro do campo de estágio, tendo em vista que é o principal protagonista do seu aprendizado.

\section{5 $\mathrm{O}$ processo avaliativo do estágio}

Uma das formas de avaliação dos estagiários de Psicologia na IES onde se realizou a pesquisa acontece por meio da escrita de um relatório, em cada semestre, dos estágios básico e específico, compondo um terço da nota final. Esse relatório é avaliado pelo orientador acadêmico.

O estagiário também é analisado por suas habilidades e competências. Essa análise é realizada pelo supervisor local e pelo orientador acadêmico a respeito da postura e prática do estagiário. Durante o desenvolvimento do estágio, acontece a avaliação parcial na metade do semestre e, posteriormente, a avaliação final no momento de finalização do estágio.

Durante o Estágio Supervisionado Básico I, a função do estagiário é se voltar à observação do campo de estágio e integrar equipes de atendimento, desenvolvendo práticas do núcleo comum da formação. Nesse primeiro contato, ele deve identificar possíveis demandas e, a partir disso, pensar em um projeto de intervenção. Esse projeto deve ser colocado em prática durante a realização do Estágio Supervisionado Básico II.

No Estágio Supervisionado Específico I e II, a função principal do estagiário é que se experimente de modo mais autônomo, propondo intervenções e realizando práticas de forma mais protagonista. Além disso, ele pode ainda participar de atendimentos em parceria com colegas ou de forma individual, e deve conseguir realizar articulações entre os conhecimentos adquiridos e a prática desenvolvida. 
Em relação ao processo avaliativo, sete dos alunos entrevistados relataram que consideram o relatório de estágio um "desperdício de tempo", por não representar a prática que cada estagiário exerce dentro do campo, conforme relatos abaixo:

O pessoal vai ficar muito mais concentrado, focado no relatório do que no objetivo, suprir a necessidade da nota do que levar o estágio como mais importante. O relatório dispensa trabalho, leva mais tempo do que as funções de estágio sabe, tu poderia estar lendo e pesquisando algo pra melhorar o estágio. E não ficar gastando teu tempo no relatório [...] (E.B.4).

Eu sei que uma das notas é o relatório, e eu acho que isso não tem nada a ver com a tua prática, né, tu vai fazer um escrito, ali vai contextualizar e tal e fazer uma análise, mas eu acho que não tem fundamento assim sabe? Não vai dizer o que tu tá fazendo aqui dentro, da tua prática realmente aqui de atendimento, entende? Eu acho o relatório desperdício de tempo [...] (E.B.5).

Talvez, esses relatos tenham surgido entre os estagiários do Estágio Supervisionado Básico I, motivados pelo fato deles ainda não terem escrito o primeiro relatório, considerando que as entrevistas se desenvolveram no período inicial do semestre.

No ano de 2016, foi exigida dos acadêmicos que cursaram o Estágio Supervisionado Básico II, como parte da avaliação, a escrita de um artigo científico. Essa nova ferramenta de avaliação ainda está sendo analisada junto ao colegiado de professores do curso para definir se será mantida nos próximos semestres ou não. No entanto, conforme os relatos dos alunos que atualmente estão no Estágio Supervisionado Básico I, eles já acreditam que terão de redigir o artigo científico.

Em virtude dessa crença, apareceram nas entrevistas alguns relatos condenando a escrita do artigo, tendo em vista que nem todos os alunos têm interesse em publicações em revistas científicas, como refere a aluna: "[...] $o$ relatório sim, mas já artigo, é pra publicação [...] o relatório acho bom, mas o artigo, talvez não, porque ele é pra outra, pra outro viés né [...]" (E.B.6).

Os alunos do Estágio Supervisionado Básico I que participaram da pesquisa trouxeram ainda que a falta do Termo de Consentimento Livre e Esclarecido (TCLE) pode dificultar a submissão do artigo produzido às revistas científicas: "[...] tu tem que fazer um artigo, mas ai tu não publica o artigo por causa do termo e tal e aí, tá talvez tu vai apresentar, já é uma boa tu tem um trabalho pra apresentar em eventos mas tu apresentaria do mesmo que não tivesse o artigo [...]" (E.B.7).

Esse fato ocorre porque em muitos casos, quando o estagiário desenvolve sua intervenção no Estágio Supervisionado Básico II, ele não 
solicita a assinatura do TCLE para os participantes, e só percebe a falta e a importância desse documento no final do semestre, quando entrega o artigo final para o orientador acadêmico. Apontamentos nesse sentido não surgiram nas falas dos acadêmicos do Estágio Supervisionado Específico I, talvez isso tenha acontecido devido ao fato de já estarem mais familiarizados com a escrita de artigos.

Apesar de a avaliação ser imprescindível, de acordo com os relatos dos entrevistados, eles dão mais atenção à prática desenvolvida do que ao processo avaliativo, por concordarem que a avaliação, muitas vezes, não condiz com a postura de cada estagiário. Ainda assim, é importante que os eles sejam instigados a experienciar a prática da escrita, a buscar o embasamento teórico e a realizar articulações entre os conhecimentos adquiridos, pois isso complementa a formação do psicólogo.

\section{CONSIDERAÇÕES FINAIS}

Ao conhecer e analisar as percepções dos estagiários do curso de Psicologia a respeito do processo de estágio, entendemos que o objetivo desta pesquisa foi alcançado.

Como pesquisadoras, acreditamos ser importante ressaltar que os estagiários entrevistados demonstraram interesse e motivação em participar da pesquisa, tendo em vista que sua realização pode contribuir, através das reflexões produzidas, com alguma mudança no processo de estágio no qual os acadêmicos estão inseridos.

Por meio deste estudo, percebemos que a recuperação de conceitos estudados durante a formação se faz presente na prática dos estagiários. Isso reforça o fato de que a teoria e a prática se complementam, sendo ambas essenciais para um bom desempenho das funções inerentes ao estágio e também do psicólogo. Esse bom desempenho é favorecido pela carga horária, que permite a experimentação e a absorção do conhecimento.

A supervisão e a orientação de estágios colaboram para nortear a prática dos estagiários, amparando-os nas suas dificuldades. Em relação ao processo seletivo, apesar da ansiedade produzida, essa fase representa um ganho de experiência para as seleções futuras, o que também caracteriza um aprendizado.

Quanto ao processo avaliativo, podemos concluir através das entrevistas que os estagiários dão maior importância à prática que desenvolvem nos campos de estágio do que à avaliação propriamente dita. Isso representa o quanto os estágios se fazem valorosos para os acadêmicos, pois, muitas vezes, apareceu nas falas dos entrevistados o quanto aguardaram por esse momento da graduação e o quão desafiador ele é, ao mesmo tempo em que se trata de uma concretização dos conhecimentos adquiridos.

Este estudo é concluído deixando como sugestão que mais pesquisas sobre esse tema sejam produzidas. Também se recomenda que espaços de 
escuta entre os estagiários e coordenação do curso sejam abertos, com o objetivo de propiciar reflexão e uma maior participação dos acadêmicos na construção do processo de estágio.

\section{REFERÊNCIAS}

ALMEIDA, Suênya T. S. de. A importância do estágio supervisionado na formação profissional do assistente social. In: SIMPÓSIO MINEIRO DE ASSISTENTES SOCIAIS, 3, Belo Horizonte, 2013.

BANOV, Márcia R. Recrutamento, seleção e competências. 3. ed. São Paulo: Atlas, 2012.

BRASIL. Lei n ${ }^{\circ} 11.788$, de 25 de setembro de 2008. Dispõe sobre o estágio de estudantes e dá outras providências. Diário Oficial da União, Brasília, 26 set. 2008.

BRASIL. Ministério da Educação. Conselho Nacional de Educação. Câmara de Educação Superior. Diretrizes Curriculares Nacionais para os cursos de Graduação em Psicologia. Resolução CNE/CES 5/2011. Diário Oficial da União, Brasília, DF, 16 de março de 2011. Seção 1, p.19.

BURIOLLA, Marta A. F. O Estágio Supervisionado. 3.ed. São Paulo: Cortez, 2001.

CAMPOS, Dinael C. de. Atuação de estagiários em Psicologia do Trabalho com grupos. Rev. SPAGESP, Ribeirão Preto, v. 10, n. 1, p. 53-59, jun. 2009. Disponível em <http:/ / pepsic.bvsalud.org/scielo.php?script=sci_arttext\&pid=S16779702009000100009\&lng=pt\&nrm=iso $>$. Acesso em: 8 mar. 2017.

CARVALHO, Maria Teresa de M.; SAMPAIO, Jáder dos R. A formação do Psicólogo e as áreas emergentes. Rev. Psicologia, ciência e profissão, Brasília, v. 17, n. 1, p. 14-19, 1997.

CENTRO UNIVERSITÁRIO UNIVATES. Centro de Ciências Biológicas e da Saúde. Resolução 080/Reitoria/UNIVATES. Projeto Pedagógico do Curso de Psicologia-PPC, 22 de setembro de 2015. Assessoria Jurídica FUVATES/UNIVATES.

CONSELHO FEDERAL DE PSICOLOGIA (CFP). Conselho Regional de Psicologia de São Paulo. Associação Brasileira de Ensino de Psicologia. Carta de Serviços sobre Estágios e Serviços-escola. Brasília, 2013.

CREMONESE, T. S.; MARQUES, I. R. Significados das primeiras experiências do estudante de enfermagem nos estágios clínicos. Rev. Enferm. UNISA, v. 12, n. 2, p. 9499. 2011.

FERREIRA, Ananda. Estou entrando em estágio curricular supervisionado, e agora? 2015. 45 f. Monografia (Graduação) - Curso de Psicologia, Centro Universitário UNIVATES, Lajeado, 2015. 
FISCHER, ROSA MARIA BUENO. Foucault e a análise do discurso em educação. Cad. Pesqui. [online]. 2001, n.114, pp.197-223. ISSN 0100-1574. Disponível em http:/ / dx.doi.org/10.1590/S0100-15742001000300009.

FOUCAULT, Michel. A ordem do discurso: aula inaugural no College de France, pronunciada em 2 de dezembro de 1970. 22. ed. São Paulo: Edições Loyola , 2012.

FRANÇA, Ana Paula de A.; SOUZA, Larissa. J. F. de. Estágio em serviço social e o processo de formação profissional: entre rebatimentos e possibilidades. In: CONGRESSO INTERNACIONAL DE POLÍTICA SOCIAL E SERVIÇO SOCIAL: Desafios Contemporâneos, 1, Londrina, 2015.

GIL, Antônio C. Como elaborar projetos de pesquisa. 5. ed. São Paulo: Atlas, 2010.

MAFUANI, F. Estágio e sua importância para a formação do universitário. Instituto de Ensino superior de Bauru. 2011. Disponível em: <http:/ / www.iesbpreve.com.br/ base.asp?pag=noticiaintegra.asp\&IDNoticia=1259>. Acesso em: 17 mar. 2017.

MINAYO, Maria Cecília de S.; SANCHES, Odécio. Quantitativo e qualitativo: oposição ou Complementaridade? Cadernos de Saúde Pública, Rio de Janeiro, v. 9, n. 3, p. 239-262, jul/set., 1993.

NASCIMENTO, M. L.; COIMBRA, C. M. B. Análise de implicações: desafiando nossas práticas de saber/poder. In: GEISLER, A. R.; ABRAHÃO, A. L.; COIMBRA, C. M. B. (Org.). Subjetividade, violência e direitos humanos: produzindo novos dispositivos na formação em saúde. Niterói, RJ: EDUFF, 2008. p. 143-153.

NETO, J.L. F. (2010). Uma genealogia da formação do psicólogo brasileiro. Memorandum, 18, 130-142. Retirado em 06 de jun. 2017 da World Wide Web. Disponível em http:/ / www.fafich.ufmg.br/ memorandum/a18/ferreiraneto01.pdf.

RUDNICKI, Tânia; CARLOTTO, Mary S. Formação de estudante da área da saúde: reflexões sobre a prática de estágio. Rev. SBPH, Rio de Janeiro, 2007, v. 10, n. 1, p. 97110.

SCALABRIN, Izabel Cristina; MOLINARI, Adriana M. C. A importância da prática do estágio supervisionado nas licenciaturas. Rev. Unar, v. 7, n. 1, 2013. Disponível em <http:/ / revistaunar.com.br/cientifica/volumes-publicados/volume-7-no1-2013>. Acesso em 15 mar. 2017. 